\title{
Editorial: Editorial Board Communication System
}

Our journal started six years ago in response to the opinions of many researchers around the globe that there was a need of an on-line, peer reviewed, scholarly journal which could address fundamental issues of electronic commerce research and practice. One reason for this opportunity was the rapid evolution of electronic commerce. The continuing changes in the technological innovations on which business patterns are based, as well as cultural, social and legal acceptance of remote transactions and information transfer, gave support to presume that the opportunity would grow in the short term. We would like to thank our Editorial Board members for being part of the team of researchers that have actively collaborated to the creation and development of the Journal of Theoretical and Applied Electronic Commerce Research.

This time we present and welcome the new Web-based system for managing the communication among Editors and the members of the Editorial Board of the Journal of Theoretical and Applied Electronic Commerce Research. This system permits editors to create and suggest activities for the participation of the Editors and Editorial Board members. We will also automatically obtain statistics of the members' participation and we will not have to ask the members to self-evaluate their contribution to the journal. Through this system we will also be able to select the candidates for the best reviewer of the year award; evaluate and select new reviewers; evaluate and select new members of the editorial board; and also select the best published papers.

The system will also allow Editorial Board members to send their suggestions (e.g., new strategies, policies, processes, procedures, ideas, organization of special issues, proposal of guest editors, etc.) with the purpose of improving the journal quality. In this system, these proposals are called suggested activities. We will discuss and evaluate these proposed activities in the editors committee.

We expect to count with the great support and contribution of our Editorial Board members through this web-based system. Editorial Board members may develop a diversity of activities to contribute to the development and continuous improvement of our journal. Most activities are defined as general activities and all members will be able to actively participate with replies and/or comments if they think appropriate. These activities are defined as public and visible to all members. On the other hand assigned activities are those activities that the Editor assigns to specific member(s) in complete agreement among the involved parties. The assigned activities may be public or private. The feedback provided by Editorial Board members when replying to or commenting on general and/or assigned activities will promote a healthy professional discussion regarding important issues, to develop or improve different aspects of the journal.

We consider that the implementation of this new communication system as a step forward in our constant search for new strategies and procedures to improve the work among Editorial Board members, and the quality of our journal. We express many thanks to our Editorial Board members for their collaboration regarding this matter, because the appropriate use of this system will allow us to make the communication among ourselves more effective and efficient, while contributing toward making better decisions.

\section{Narciso Cerpa}

Editor-in-Chief

Journal of Theoretical and Applied Electronic Commerce Research

www.jtaer.com

December 2011 